\title{
Fragmentos de Etnografia Xokleng no Século XIX em "Questão de Limite entre Paraná e Santa Catharina"
}

\section{Ethnography Xokleng fragments in the nineteenth century on "Boundary Issue between Paraná and Santa Catharina"}

\author{
Walmir Pereira
}

O que deve, entretanto, ficar evidente é ser a raça dos botocudos do sul, quer physica, quer intellectualmente, bastante distincta das dos outros selvicolas das provincias de Santa catharina e Paraná, com os quaes vivem sempre em guerra.

Encarados pelo lado intellectual, sam intelligente, porém, como é natural, de intelligencia agreste que só se manifesta por actos de sagacidade, astucia e paciencia, para os quaes foram preparados pelo evoluir de milhares de gerações. (Jaques Ouriques, 1887)

Entre o último quartel do século XIX e o começo do século XX, a área territorial abrangida entre o norte, o noroeste catarinense e o sudoeste paranaense era sinônimo de "rudeza" e de "terras devolutas". Essa área foi motivo de intensa disputa de limites entre as províncias - posteriormente estados - do Paraná e Santa Catarina, litigio que acabou originando o conflito épico do Contestado. Os ocupantes dessa região eram indígenas Kaingang e Xokleng, fazendeiros ou, ainda, pessoas miscigenadas e peões de fazenda que ocupavam a terra como posseiros.

Mister a lembrança de que em pleno limiar do século passado, em parte dessa paisagem contínua e monótona, território ${ }^{1}$ onde até então os Xokleng tinham sido os senhores

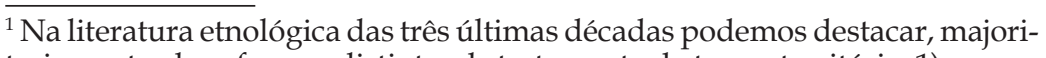
tariamente, duas formas distintas de tratamento do termo território: 1) espaço
* Antropólogo, Professor no Cursos de Ciências Sociais da Unisinos. Diretor do Museu Antropológico do Rio Grande do Sul (MARS).

E-mail:walmir@unisinos.br 
absolutos, imagem de um universo percebido como áspero e "primitivo", na então província de Santa Catarina, deu-se início à incorporação desse cenário transformando-o em objeto de diferentes projetos de desenvolvimento. Traçando esse objetivo em pauta estratégica, os governos republicano e provincial decidiram pegar o "trem da história" e do "progresso", símbolo da modernidade que começa a se configurar no Brasil Meridional.

Frente a tal conjuntura histórica sinteticamente esboçada aqui, Jaques Ourique, militar integrante do exército imperial, que percorreu a região do contestado em 1882 integrando uma comissão mista de discriminação de terras e limites, e cujo trabalho foi concluído em março de 1884, produziu um importante relato etnográfico sobre a presença dos Xokleng no espaço da região sulina. Em sua descrição, o autor busca evidenciar as dificuldades enfrentadas pela expedição em território de ocupação tradicional Xokleng: “Porquanto tínhamos de atravessar considerável extensão de desertos desconhecidos, habitados por índios e feras sem podermos avaliar ao certo os dias de demora, nem presumir qual a natureza dos elementos a vencer, e ainda mais penosa tornou-se, por ter corrido sempre chuvoso o tempo, desde seu começo até que sahímos do rio Negro" (OURIQUE, 1887, p. 13).

A imagem agreste do sertão meridional em pleno final do século XIX surge com força na narrativa do engenheiro militar, atestando a ocupação do espaço sulino por "índios e feras", numa alusão implícita que projeta indígenas e animais ao lado da natureza em oposição à cultura ocidental. Em seu relatoexperiência, o autor produz, entre outros relatos interesantes, uma consideração quanto à possibilidade de ataque Xokleng: "o índio das paragens que íamos atravessar, bem que indomável e feroz, só ataca com todas as garantias de êxito completo, e eu tinha o meio de não lh' as dar conservando vigilantes sentinellas durante a noite e tomando as demais precauções necessárias".

Em uma outra passagem interessante de seu relatório, desponta a postura adotada frente a experiência de um possível contato com os Xokleng: "Sentimo-nos sempre sob a vigilância do índio sagaz e astuto, mas nunca o podemos ver, porque também nunca demos ensejo de se mostrarem".

Os Xokleng, equivocamente identificados como Botocudos na visão do autor,

do grupo utilizado à sua reprodução física e cultural, "no sentido em que é usado de território habitado por um determinado grupo social"; e enquanto 2) espaço sócio-político e histórico ativamente assumido como do grupo, no sentido de que este território ou territorialidade de um grupo "é também objeto de disputa ou uma das formas que esta disputa assume - seja entre índios e não índios, seja entre os prórios índios, em caso de facções." (LEITE, 1993, p. X). Para uma discussão ampla e estreitamente vinculada à questão da reelaboração cultural e à proposta de análise e monitoramento da situação das terras indígenas num contexto específico, ver Oliveira Filho e Leite (1993, p. V-XV). 
[...] "fogem a todas as tentativas de catechese com horror, e preferem a morte a viver ou manter relações com homens civilizados" [...] Indomáveis e nômades ao último extremo, a isso levados pela continua guerra que lhes têm feito os brancos, habitam, estes selvagens, uma facha de sertão cercada por todos os lados de povos, villas e cidades, conservando, entretanto, no coração dessas matas quasi virgens, seus habitos primitivos. ${ }^{2}$

Dado significativo que chama a atenção do pesquisador é o fato de o manuscrito original, inserido como parte terceira do documento Questão de Limites entre o Paraná e Santa Catharina, composto de 59 páginas e que originalmente veio a lume em 1887 na Revista do Exército Brasileiro ${ }^{3}$, consagrar integralmente a terceira parte da obra para produzir informações etnográficas e descrever a experiência de contato vivenciada por Jaques Ourique com informante criança Xokleng que, em suas palavras e entendimento, "conserva[va] todas as reminiscencias da vida das selvas e ainda joga com o dialecto dos seus, [...] sendo que sua "narração é concisa, clara e onomatopaica" (OURIQUE, 1887). Do mesmo modo, signifcativo é a presença de um conjunto de vocábulos da língua Xokleng que, salvo melhor juízo e eventual descoberta ulterior, constitui-se em aporte precioso e um dos vocabulários iniciais copilados pelos agentes do mundo ocidental referentes a este povo Jê Meridonal.

Por fim, mister o registro que, em sua totalidade, a narrativa transcrita por nós pode ser emoldurada na perspectiva de uma espécie de relato testemunhal de antigos oficiais veteranos da Guerra do Paraguai preocupados com a memória institucional e, particularmente, interessados em influenciar o contexto sociopolítico, em vias de transição, vigente entre o período monárquico imperial e o advento da foram de governo republicana inaugurada no país em 1889.

\title{
Questão de Limites entre Paraná e Santa Catarina
}

\author{
Alfredo Ernesto Jacques Ourique
}

\section{Parte III - Ethnographia}

Desde as matas luxuriantes que vestem as encostas maritimas da Serra do Mar até o rio Timbó na bacia hydrographica dos rios Negro e Iguassu ao norte da zona, e até o rio do Peixe na bacia do Pelotas ao sul, dominam em toda a região contestada os indios conhecidos impropriamente por botocudos.

\footnotetext{
${ }^{2}$ Ourique, 1887, p. 25.

${ }^{3}$ Primeiro periódico científico do Exército brasileiro, a Revista foi criada em 1882 com a atribuição de ser o veículo oficial do conhecimento produzido na instituição. (Referência: OURIQUE, Alfredo Ernesto Jacques. Questão de Limite entre Paraná e Santa Catharina. Rio de Janeiro : Typographia da Revista Exercito Brasileiro, 1887).
} 
Indomaveis e nomades ao ultimo extremo, a isso levados pela continua guerra que lhes têm feito os brancos, habitam, estes selvagens, uma facha de sertão cercada por todos os lados de povos, villas e cidades, conservando, entretanto, no coração d'essas, quasi virgens, seus habitos primitivos.

Emquanto os coroados e outras tribus que vivem dos rios Timbó e do Peixe para o oeste e que, na voz dos sertanejos, reconhecem estes dous rios como limites de suas possessões com as de seus visinhos e inimigos - os botocudos, a quem muito temem, já se acham meio civilisados; os indios em questão fogem a todas as tentativas de cathechese com horror, e preferem a morte a viver ou manter relações com homens civilisados.

Algumas crianças e mulheres têm cahido por varias occasiões, em poder dos moradores das cercanias do sertão, após lutas onde muitos morrem, mas não ficam sobre o campo da contenda, pelo grande cuidado de seus companheiros em conduzir-lhes os cadaveres.

D'estas crianças e mulheres poucas têm ficado entre os brancos, voltando para o sertão ou morrendo a maior parte.

Duas vezes tentou a catechese d'estes aborigenas o intrepido e lendario sertanejo Joaquim Francisco Lopes, irmão do heróico guia da expedição de Matto Grosso - José Francisco Lopes.

Estes denodados mineiros tinham, de certo, nas veias o sangue intrepido dos primeiros bandeirantes, pois, as excursões longinquas se haviam tornado uma necessidade para suas indoles aventureiras e corajosas.

Não é dado ao militar brasileiro passar em silencio sobre o nome de José Francisco Lopes, o salvador da expedição de Mato Grosso, sem render-lhe o devido preito.

Foi elle que a guiou, desmantelada e abatida, conservando a vida abalada pela cholera, somente o tempo necessario para mostrar-lhe o caminho do salvamento.

A patria levantou-lhe uma cruz no meio do deserto; um militar - Taunay - deu-lhe um logar na historia, em sua Retirada de Laguna.

Em 1868 fez Joaquim Francisco Lopes duas diligencias, na zona contestada com o fim de trazer á civilisação os indios botocudos, sendo ambas infructiferas.

Em 1877 foi encaregado pelo governo de fundar um aldeamento para reducção d' esses selvagens, na estrada de Lages, cerca de 5 leguas distante da villa do Rio-Negro, ao qual deu elle o nome de S. Thomaz de Papanduva.

Com todo o tino filho de uma convivencia de longos annos com os selvicolas, com brindes e promessas bem dirigidas, tentou Joaquim Lopes trazer ao aldeamento os selvagens. Não lhe foi possivel alcançal-o. 
Uma vez teve-os á falla, porém nada obteve. As suas propostas, formuladas em um dialecto suppunha ser por elles entendido, aos seus gestos amigaveis, aos brindes, á aproximação desarmada, respondiam, os bugres, com gritos roucos e ameaçadores e não se mostravam.

Nesse mesmo anno de 1877 foi extincto o aldeamento, apesar dos protestos de Lopes, que ainda conservava esperanças de reduzir o gentio, nada mais se fazendo nesse sentido.

Um sueco, o sr. Martim Maeder, habitante da villa do Rio-Negro, homem, tambem muito dedicado a estas questões de catechese de aborigenes, em uma de suas excursões ao sertão aprisionou um indiosinho de cêrca de 14 annos de idade.

Trouxe-o para a villa, afagou-o no seio de sua familia, levou-o á capital da provincia, tirou-lhe o retrato e, de volta para o Rio-Negro, soube que os indios botocudos rondavam todas as noites os matos visinhos de sua casa, com o fim de furtar-lhe o bugrinho, o que decidiu a não conserval-o comsigo.

Esta criança, bonita e bem constituida, tinha o cabello completamente rapado, não usava tanga e simplesmente trazia como adorno um T de madeira bem polida, suspenso de um furo no meio do labio inferior, com a perna vertical vertente para o exterior, e cordas de embira enroladas em volta dos tornozellos e dos pulsos, as quaes afrouxava quando queria correr ou fazer qualquer outro exercicio.

Mostrava-se muito admirado e muito observador de tudo quanto via, principalmente dos vidros das janellas, que, continuamente, lhe prendiam a attenção. Revelava especial cuidado e dedicação para com o filhinho mais novo do sr. Maeder, criança de poucos mezes, correndo a tocar no braço deste senhor assim que o via chorar.

Conservou-se pouco mais de um mez no Rio-Negro e nunca pronunciou palavra alguma.

Uma noite logrou fugir; venceu a nado o rio, muito correntoso neste ponto, e já atravessava a estancia do sr. Antonio Ricardo com direcção as mattas, quando, denunciado pelos cães, foi seguro e de novo levado para a casa do sr. Maeder, que resolveu dar-lhe liberdade.

Cobriu-o, para isso, de presentes, carregou-o de roupas e ferramentas, e dirigiu-se com elle ao lugar onde o aprisionara. Ahi, deixando-o só, viu-o logo correr em direcção ao mato onde desappareceu.

Tempos depois, sendo aprisionado um outro indiosinho nos mattos da Estiva, o qual está hoje no Rio-Negro, ja falla o portuguez e não quer mais voltar para o sertão, soube-se ser aquelle filho de um cacique, sendo seu nome Covi.

Contou mais, este bugrinho, baptisado depois com o nome de Felicio, que, quando Covi fora feito prisioneiro, o cacique seu pai ficara furioso e 
ordenara aos chefes da expedição de que elle fazia parte que o fossem buscar, pois do contrario os mataria.

Estes já se achavam de volta e condemnados quando Covi appareceu, e, por isso, foram perdoados. Covi ao apresentar-se entre os seus, dissera haver fugido, roubado tudo quanto comsigo levava. Contara tambem o filho do cacique sua primeira tentativa de fuga abortada, e, é tal a clareza da narração entre os gentios, que Felicio logo de chegada indicou, sem ninguem lhe perguntar, onde ella se effectuara.

Convem dizer alguma cousa sobre Felicio, porquanto, não se podendo estudar a raça que me occupa no estado natural, deve-se procurar fazel-o o mais perto possivel desse estado.

Este indiosinho mostra contar de 7 a 8 annos de idade, tem a tez requeimada e a physionomia caracteristica dos nossos selvicolas, sendo para assignalar a harmonia das linhas, que como em Covi, talvez em consequencia da idade, fazem lembrar o rosto das donzellas indigenas, mormente quando, na interrogação, volvem meigamente os lindos olhos negros e rasgados.

No avelludado humido do olhar, no expandir da physionomia, brilha nessas ocasiões tal intellgencia, que faz esquecer a proveniencia do bugrinho.

Intelligente, manhoso e astuto, tem aprendido tudo quanto se lhe tem ensinado, revelando facilidade de apropriação, boa memoria e grande tino observador.

Ainda caminha com os braços pendentes e [ilegivel], cabeça baixa e corpo meio curvado para a frente, costumes adquiridos pelo habito de romper matto; e, assim que se assusta, começa logo e instinctivamente, a andar sobre o lado externo dos pés para occultar o rasto.

Neste caso, quanto a mim, trabalha mais a herança do que a pratica, a vista da sua pouca idade.

Felicio, como Covi é dotado de pés grandes e mal feitos, sendo este um traço caracteristico da raça a que pertence.

Conserva todas as reminiscencias da vida das selvas e ainda joga com o dialecto dos seus, que deve, entretamto, resentir-se em sua bôcca da má expressão proveniente da pouca idade.

Sua narração é concisa, clara e onomatopaica.

Muitos dos apontamentos, que dou em seguida, foram-me por elle fornecidos, com certa timidez natural, porém com muito tino; e, nunca me hei de esquecer, da prescisão com que me descreveu o Salto do Canoinhas, que me contou haver atravessado muitas vezes as costas de seus pais.

Disse, ao começar, que julgava impropria a designação de botocudos dada a essa raça. 
Como é sabido esse qualificativo proveiu a certas tribus brasileiras do uso de grandes botoques que, pelo tamanho e peso, lhes deformavam os beiços e orelhas.

Com os botocudos do Parana e Santa Catarina não se dá isso.

O chamado botoque não passa de um pequeno adorno de madeira pendente do labio inferior atravez de um orificio nunca maior de um centimetro de diametro.

Não usam, além desse, qualquer outro enfeite, trazendo, alguns, o cabello, que os adultos usam crescidos, atados em uma tira larga de embira conforme asseveram algumas pessoas que tem tido ocasião (sempre rara) de vel-os conservando a vida.

Vivem em continua emigração de serra acima para serra abaixo, conforme, tempo de pinhão na zona do planalto ou de outros fructos na zona maritima.

Não só os fructos procuram nestas correrias, como a caça que com elles apparece mais facil e abundante.

Seus ranchos, em virtude desta vida bohemia, sam provisorios e em logares incertos.

Feitos de varas que, muitas vezes, nem cortam, contentando-se em arcál-as e atál-as pelas extremidades superiores, sam cobertos de palmas de jerivá, jissara, ou mesmo de ramas de arbustos.

Pela disposição dos fogos, cujos vestigios se tem podido observar, costumam deitar-se com os pés voltados para meio do rancho, ateando pequenas fogueiras nos intervallos que ficam entre ás solas de duas filas de dormentes.

É voz geral entre os sertanejos, porém nada de positivo a confirma, que, além destes ranchos passageiros, possuem os bugres um grande toldo no coração das matas, onde tem seu quartel general, sua malóca, com plantações de cereaes, ranchos bem feitos e até forjas.

Esta lenda da forja é tirada da perfeição com que trabalham elles todo o ferro que lhes cahe nas mãos, para reduzil-o a pontas de flecha.

As armas que mais usam sam: o arco e a flecha com ponta de ferro ou madeira, o arco ou viróte para caça e a massa de madeira com quinas, de cerca de metro e meio de comprimento.

É 'esta sua principal arma de guerra, a qual costumam deixar sobre o corpo da victima.

Talvez pelas necessidades de sua vida erratica, cremam os seus mortos.

Para esta cremação, collocam o corpo numa área circular de terreno, previamente preparado e pisado e sobre elle formam uma pilha conica de madeiras unidas na extremidade superior. Accesa a fogueira esperam que 
esteja tudo reduzido a cinzas e, então, enterram estas cinzas em uma pequena sepultura.

Havendo grandes desejos de obtenção de um craneo de botocudo destas paragens, varias sepulturas tem sido revolvidas, só se encontrando cinzas e ossos meio carbonisados.

Não conhecem o direito de propriedade sinão em um de seus principios fundamentaes - a caça pertence a quem abateu-a.

Si cães, quer de indios quer de sertanejos, correm uma anta, si é o sertanejo que chega primeiro á acuação e mata, o indio se retira qualquer que seja o numero, si é o indio toca ao sertanejo retirar-se.

Apezar de tacita é esta convenção muito respeitada, segundo me afirmaram experimentados caçadores de antas.

Como consequencia de sua ignorancia tem elles o habito de pilhar as roças de milho, que não plantam mas muito apreciam; costumam matar ou roubar animaes para comer, preferindo burros e cavallos; dam muito valor ás ferramentas de uso da lavoura e aos objectos de ferro, que furtam, sempre que podem.

Desta pilhagem que, para o pobre e ignorante selvicola, é um direito legitimo, tem nascido a lucta atróz de represalias que os traz horrorisados e arredios da civilisação.

E como não ser assim?

Para o indio estupido e covarde, para a raça em decadencia moral e physica, possivel é o amortecimento da natural altivez e brio patrio e o esquecimento do captiveiro, do abuso e do morticinio levados ao seio das tabas em nome dessa civilisação; mas, para o selvagem intelligente e corajoso, só exprime ella, desde seculos, o aniquilamento, a devastação e a ruina, contra os quaes combate.

Quanto a mim, o indio que acceita a catechese, entre nós, representa uma raça inferior, ou os restos abastardos e corrompidos de uma grande raça.

As grandes tribus, as raças superiores, a aristocracia indigena em fim, jamais acceitaram uma civilisação que só se lhes revela pela mais cruel barbaria.

Estas luctam energica e tenazmente pela vida, mas não se submettem a um captiveiro que as degrada, a uma posição que as enfraquece e desarma para a eterna pugna.

É' o proprio instincto da raça, condição evidente de superioridade, a indicar-lhes o unico meio em que devem combater para poder transmittir ao trabalho da evolução os aperfeiçoamentos conquistados.

A catechese, para ellas, é a renuncia ás prerogativas herdadas, é a acceitação do domínio absoluto, é o desarmamento physiologico e material para o combate pela existencia, o stuggle for life. 
Antes do descobrimento do novo mundo, emquanto na Europa os povos evoluiam, havia, tambem, uma outra evolução, independente mas parallela a essa, entre os povos da America, em meio bem differente.

Desde que, porém, foram postos em contacto o velho e o novo continente, as raças americanas, como que retrogadaram e tendem a desapparecer, vencidas na lucta desigual, para a qual foram sorprehendidas e não se achavam preparadas pelo trabalho de seculos, com seus adversarios.

Entretanto luctam sempre e mais energicas e tenazes se tem mostrado aquellas que mais adiantados se achavam.

Os botocudos do sul physicamente considerados, sam altos, robustos, bem conformados e dotados de physionomia regular e simpathica.

Dizem existir entre elles alguns de têz clara e cabellos arruivados ou louros. Não sera para estranhar este facto desde que se saiba haverem os indios, por mais de uma vez, roubado creancinhas, filhas dos colonos estrangeiros estabelecidos nas cercanias do sertão e tel-as conservado comsigo.

Sua força muscular e elevada estatura sam proverbiaes em ambas as provincias.

Acredito como o principal fundamento desta tradição o facto de serem, quasi sempre, vistos os selviclas, nas expedições perigosas para as quaes devem escolher os mais robustos e alentados dentre os seus.

Não quero contestar, com esta observação, a robutez e estatura elevada da raça que estudo, somente faço uma ponderação cautelosa a um facto geralmente acceito, porém, ainda mal confirmado.

O que deve, entretanto, ficar evidente é ser a raça dos botocudos do sul, quer physica, quer intellectualmente, bastante distincta das dos outros selvicolas das provincias de Santa Catharina e Paraná, com os quaes vivem sempre em guerra.

Encarados pelo lado intellectual, sam intelligente, porém, como é natural, de intelligencia agreste que só se manifesta por actos de sagacidade, astucia e paciencia, para os quaes foram preparados pelo evoluir de milhares de gerações.

Não se percebe, nos objectos que usam hoje, o gosto artistico manifesto, ainda que elementarmente, na arte ceramica de certas tribus do norte.

Seus arcos, suas flechas, seus tecidos sam singelos, mas não toscos; dessa singelesa marcial, caracteristica dos costumes e usos das tribus guerreiras.

Conhecem, de ordinario, os nomes de todos os habitantes das immediações do sertão, e conservam por longos annos a physionomia da pessoa que tenham visto uma vez. 
Servem-se perfeitamente do facão, da foice e do machado, golpeando, porém, com estes, da esquerda para a direita ao inverso dos sertanejos.

Imitam, com rara facilidade, não só passaros e outros animaes, como as pessoas.

Por mais de uma vez o servente que tinha a balisa no estaqueamento das picadas a fixava, ao ouvir a voz do agrimensor gritar - ahi-, emquanto que este nada dissera.

Era o selvagem que acompanhava o serviço das turmas, occulto no matto, só se manifestando por estes ou por outros identicos actos de agreste intelligencia e pueril divertimento.

Conhecendo a desvantagem com que sempre entram na luta contra os brancos, premunem-se de todas as garantias e cautelas necessarias a equilibrar as condições do combate, sinão a destruir as vantagens adversas.

Desse modo, com raro tino estratégico e tactico, escolhem o logar mais apropriado para o ataque; aguardam durante dias ou mezes, a ocasião mais propicia; e, quando cahem sobre o adversario desprevenido, tem por si todas as presumpções não já da vitoria, mas do seu aniquilamento completo.

O sertanejo vê nestes actos de intelligencia, manifestações de covardia, e condemna o bugre como estupido e ignorante, porque não se atira nú e armado de simples cacetes ou arcos, cujas flechas se desviam com o menor obstaculo, ao encontro das balas certeiras de suas carabinas e do golpe afiado de suas adagas.

Na defesa mostram, tambem, intelligencia e grande estudo do modo de atacar de seus adversarios, cujos erros ou habitos aproveitam com notavel sagacidade.

Jamais dam ou acceitam combate em que não tenham todas as probabilidades em seu favor, como já o disse, e, sobretudo, de que não tirem alguma utilidade material.

Vou citar um exemplo.

Distante poucas leguas do campo da Estiva existe um corrego que, sahindo da mata em declive, corta as capoeiras que marginam a estrada de Lages, atravessa esta formando perigoso atoleiro e entra de novo no matagal que, em toda as direcções se estende a perder de vista por fundos valles e altas serras.

É este ponto denominado Passo-Ruim, por causa d'aquelle tremedal, onde tem deixado, as tropas que percorrem esses caminhos, muitos animais mortos.

Apezar da má reputação dada a este logar pelas repetidas correrias dos bugres, não raro, os tropeiros que se dirigiam ou voltavam de Lages e Campos-Novos, ahi faziam pouso, tanto mais descuidados quanto menos recentes as noticias de tropelias de bugres no sertão. 
Eram os sertanejos devedores aos bugres de uma represalia, de que pareciam estes já se haver esquecido, quando deu-se o facto que vamos narrar e caracterisa perfeitamente a paciencia com que aguardam elles a vingança, com que a preparam e a intelligencia em desenvolver no ataque e na defesa só aproveitando todas as circunstancias favoraveis e neutralisando as contrarias.

Ao declinar de uma tarde do anno de 1866, uma tropa conduzida por seis homens e um menino de 12 a 14 annos, que vinha da Estiva com direcção ao sul, parou no Passo Ruim para pernoitar.

Solto os animaes, arrumadas as cargas, empilhadas as cangalhas, fizeram fogo os tropeiros, penduraram a caldeira do feijão e deixando o menino encarregado da cosinha, estenderam-se alli mesmo sobre a grama e logo adormeceram.

Pesado devia ser o somno, porquanto, haviam passado toda a noite anterior em um fandango, montando pela madrugada e seguindo caminho, sem haver pregado olho. Fervia o feijão e dormiam os tropeiros, quando o menino se dirigiu pelo matto ao corrego proximo, em procura d'agua.

N'essa occasião sahiram, com toda cautela, varios bugres da capoeira, que os occultara até então, dirigiram-se aos dormentes e com seis pancadas certeiras de cacete abriram-lhes os craneos.

Uma das pancadas não foi bem firme e a victima levantou-se atordoada querendo luctar, mas, novo golpe a prostrou, a poucos passos, sobre uns galhos seccos.

Em quanto isto se dava na clareira junto á estrada um indio extremamente alto e corpulento, atacava o menino no mato e fendia-lhe a cabeça até quasi o pescoço, com formidavel cacetada.

Acto continuo, esvasiaram os selvagens os saccos, aposaram-se das armas das victimas, tiraram todas as ferragens das cangalhas e de alguns barris de cachaça, que com os sacos de assucar e sal formavam a carga da tropa, viraram os mortos de bruços e pousando-lhes os cacetes ao longo das costas partiram com os despojos.

No seguinte dia, o primeiro caminheiro que por alli passou viu a carnificina e a noticia vôou até a villa do Rio-Negro donde partiu o subdelegado, acompanhado de poucas praças e alguns sertanejos, a verificar o facto e perseguir os criminosos.

N'essa verificação a paciencia e pratica dos homens do sertão construiram, pelos factos visiveis, a scena de que não ficara testemunha, tal qual a narramos.

Assim foi que pelo estado do feijão, meio cosido e sem agua, e do fogo apagado e com pouca cinza, colligiram ter sido o ataque ao anoitecer e pouco depois da tropa chegar; pela altura de um galho quebrado pelo cacete quando descia sobre a fonte do menino, a estatura do bugre que o ferira etc... 
Verificaram, ainda, pela abertura circular feita em uma moita próxima e pelo signal da pressão deixada, atraz d'esta, por um corpo humano que, durante mais de seis mezes, fôra aquelle pouso constantemente vigiado pelos indios á espera de ocasião propicia, a qual, finalmente, a fatalidade lhes apresentara tão a geito.

Enterrados os mortos e plantadas sobre as sepulturas 7 cruzes, que ainda tive a ocasião de vêr, quando passei por este ermo e sinistro lugar, a expedição seguiu no rastro dos fugitivos.

Um dia depois chegou a um ponto do sertão, onde se via estreita trilha pela qual enveredaram cautelosos.

Inesperadamente, pouco antes de acabar a trilha divisaram na clareira onde esta ia dar, alguns ranchos de construcção recente e, n'um destes, evidentes mas não tanto a causar suspeitas, alguns objectos, como um cestinho de taquara, um arco etc., os quaes sam muito apreciados no sertão pela procura que têm.

Para logo, os homens da testa da fileira que seguia pela trilha prepararam as armas e avançaram com os olhos fitos na clareira e nos objectos que distinguiam.

De subito o da frente pisou terreno falso e cahiu n'um fojo, os dois immediatos, por um movimento instinctivo recuaram sobre os da retaguarda e sahindo da trilha, lateralmente, cada um para seu lado, cahiram tambem em outros dous fojos.

Já então os companheiros, percebendo a especie do perigo, se conservavam immoveis e promptos a receber os bugres.

Claro está que estes, tendo alcançado seu fim, não correriam os riscos de um ataque.

E esse fim era fazer voltar a expedição o que obtiveram, pois, seria rematada loucura continuar a perseguição, conduzindo tres homens feridos gravemente pelos aguçados estrepes dos fojos, e nem lhe restava o recurso de se dividir em duas turmas, voltando uma e seguindo a outra, por ser pouco numerosa.

Haviam portanto tirado completa vingança os selvicolas, mas, a serie das represalias continuaria, e, eram elles, agora, os devedores dos brancos que, conforme seus habitos, não deixariam de fazer o terrivel ajuste de contas.

Lastimavel habito este, que vai até o ponto de crearem um imposto voluntario para levantarem e manterem bandeiras de bugreiros encarregados da matança dos indigenas, sem distincção de sexo nem idade, sob a denominação ostensiva, direi mais, official de - afugentadores de bugres.

E o que ainda mais admira é terem já sido pagos estes bugreiros, em época não muito afastadas, pelos cofres publicos. 
Devo mudar de assumpto.

Como negar, portanto, aos botocudos do sul um gráo de desenvolvimento intellectual identico ao das raças mais adiantadas do Brasil, senão no presente pelo menos em épocas passadas...

Não será esta tribu, hoje reduzida pela guerra, os restos de uma grande raça que, sustada no seu progredir lento para a civilisação pelo choque brusco com um povo invasor e dissemelhante e adiantado, abandonasse seus habitos e voltasse á vida nomade, em defesa das crenças, da família e da liberdade, tanto mais cara quanto mais preparada se acha a intelligencia para dar-lhes preço.

Este amor inveterado á liberdade e aos costumes: este horror á civilisação que tão sinistramente se lhe manifestava: esta tenacidade por uma lucta que a aniquila, mas, conserva-lhes as crenças; todos estes factos que, hoje, assignalam como que um regresso ao ponto de partida, não mostrarão, também, um grande adiantamento do ponto da curva da evolução donde começou a operar-se o retorno?

Mas, então, de que grande raça sam restos os botocudos do sul? quaes os seus costumes, qual o seu habitat quando os invasores abordaram o continente americano?

Profundas e complexas questões sam estas, para quem tão baldo se tem confessado de elementos e erudição necessarias á taes pesquizas.

Talvez algum dia possa dedicar algumas horas a estes estudos e trazer meu contingente, fraco embora, a solução do problema.

Um dos mais poderosos elementos para indagações ethographicas é, por sem duvida, a lingua fallada pelo povo cujo passado se procura conhecer.

Mas, para alcançar este elemento, para fixal-o com criterio, sam necessarios longos annos de pratica, sam precisos conhecimentos especiaes e muito dicernimento linguistico.

Um vocabulario, como o que vou dar em seguida, tomado de passagem por um engenheiro em serviço de sua profissão, pouco valor têm.

Deveria consignar vocabulos e depois phases com elles formadas, mas não me foi possivel fazel-o.

Além disso, para dar-lhe claresa, era preciso escrevel-o na ortographia harmonica proposta pelo Dr. Baptista Caetano, mas presentemente, falhamme tempo e elementos e, portanto, contento-me em copiar o que escrevi na minha caderneta de campo. 


\section{VOCABULARIO}

Testa

cabellos

Orelhas

Cabeça

Olhos

Nariz

Bocca

Queixo

Lingua

Dentes

Peito

Mãos

Pés

$\mathrm{Eu}$

$\mathrm{Tu}$

Mãe

Pai

Milho (grão)

Milho (espiga)

Tigre

Grande

pequeno

Boi, cavalo, besta

Não

Rio

Coroado (indio)

coroada (india)

Casa

Rancho

Homem branco

Mulher branca

Preto (cor)

Branco

todas as demais cores

Um

Dois

Alvorada

Depois do sol nascido

Pôr do sol

Lua
I-cocáva

I-crê-uem-croquy

I-nham-crê-uem

I-crê-uem

ITy-coná-uem

I-ny-nhá-uem

I-nhá-cu-uem

I-ló-uem

Ty-ny-nha-uem

I-ny-nha-uem

Ty-nungué-uem

Ty-inungá-uem

Ty-pá-uem

I-nhá-uem

Am-á-uem

I-nhom-uem

I-ug-uem

Graconam-uem

Barabó-uem

Mem-uem

Chy

grám

Cavallú

Deyá

Goyo-uem

Guiú-uem

Guiú-si-uem

Zú-em-uem

Auá-iça-em-uem

Zug-uem

Zug-si-uem

Ty-chùm-uem

Ty-cô-plin-uem

Ty-cô-chu-uem

Ty-pery

Ty-rangre-uem

Voyó-guê-uem

Lá-jurú-uem

Lá-uem

Cochá-uem 
Torto

Direito

Não sei

Bom

Podre

Arco

Flecha

Tripa

Dormir

Toma

Da-me

Couro de tigre

Couro de tigre pequeno

Cabeça de tigre grande

Cabeça de tigre pequeno
Ty-do-yó-guem-uem

Ty-tom-ualom-chó-uem

Dy-dô-con-uem

Tinigrá-uem

Ticucré-uem

Ty-viriú-uem

Ty-do-uem

Ty-du-uem

Tim-my-uem

Inhó-zi-uem

Cha-mô-zi-uem

Mem-zoro-uem

Mem-cram-zoro-uem

Mem-chy-crê-uem

Mem cram-crê-uem

Estes vocabulos e phrases me foram dados, com bastante intelligencia, pelo indio Felicio, por isto, é muito possivel que se resintam dos vicios de linguagem proprios da pouca idade de interprete.

Devo declarar que o vocabulo uem - em que terminam quasi todas as palavras, um som aspirado que fica entre uem e uam.

$\mathrm{O}$ unico nome indigena onde vi applicado este vocabulo, foi o do rio Pelotas, chamado Goyouem.

Tambem foi este o unico nome indigena de localidade que encontrei, não pertencente a lingua guarany.

Este facto talvez exprima ter sido a zona primitivamente povoada por aquella raça, tendo vindo occupal-a, os actuaes botocudos, por migração voluntaria ou forçada.

\section{Referência}

OURIQUE, Alfredo Ernesto Jacques. Questão de Limite entre Paraná e Santa Catharina. Rio de Janeiro: Typographia da Revista Exercito Brasileiro, 1887. 